\title{
Sexual Development and the Environment: Conclusions from 40 Years of Theory
}

\author{
Lisa E. Schwanz ${ }^{a} \quad$ Arthur Georges $^{b}$ \\ ${ }^{a}$ Evolution and Ecology Research Centre, School of Biological, Earth and Environmental Sciences, University of New \\ South Wales, Sydney, NSW, Australia; ' Institute for Applied Ecology, University of Canberra, Canberra, ACT, Australia
}

\section{Keywords}

Temperature-dependent sex determination · Evolution ·

Ecology · Mechanism · Genotypic sex determination

\begin{abstract}
In this review, we consider the insight that has been gained through theoretical examination of environmental sex determination (ESD) and thermolability - how theory has progressed our understanding of the ecological and evolutionary dynamics associated with ESD, the transitional pathways between different modes of sex determination, and the underlying mechanisms. Following decades of theory on the adaptive benefits of ESD, several hypotheses seem promising. These hypotheses focus on the importance of differential fitness (sex-specific effects of temperature on fitness) in generating selection for ESD, but highlight alternative ways differential fitness arises: seasonal impacts on growth, sexspecific ages of maturation, and sex-biased dispersal. ESD has the potential to generate biased sex ratios quite easily, leading to complex feedbacks between the ecology and evolution of ESD. Frequency-dependent selection on sex acts on ESD-related traits, driving local adaptation or plasticity to restore equilibrium sex ratio. However, migration and overlapping generations ("mixing") diminish local adaptation and leave each cohort/population with the potential for
\end{abstract}

biased sex ratios. Incorporating mechanism into ecology and evolution models reveals similarities between different sex-determining systems. Dosage and gene regulatory network models of sexual development are beginning to shed light on how temperature sensitivity and thresholds may arise. The unavoidable temperature sensitivity in sex-determining systems inherent to these models suggests that evolutionary transitions between genotypic sex determination (GSD) and temperature-dependent sex determination, and between different forms of GSD, are simple and elegant. Theoretical models are often best-served by considering a single piece of a puzzle; however, there is much to gain from reflecting on all of the pieces together in one integrative picture.

(c) 2021 S. Karger AG, Basel

\section{Introduction}

Sex, the fact that a very many species present as 2 distinct phenotypes that share their genetic material during reproduction, has intrigued thinkers through the ages. Why, having survived the vicissitudes of life, does it make sense to dilute your winning formula when generating offspring? Why, when males appear to be produced in superfluous numbers (one male can fertilize many fe- 
males), are the sexes produced in roughly equal numbers in most species? Early thinkers, faced with the first definitive data from human populations, considered this numerical parity of the sexes to be clear evidence of divine influence [Arbuthnott, 1710]. Around the turn of the 20th century, evolutionary biologists began formulating explanations for a 1:1 sex ratio based on individual-level selection [Darwin, 1871; Düsing, 1884; Edwards, 1998], while geneticists debated whether environment or genetics set the course for sexual development [Brush, 1978]. The discovery of sex chromosomes seemed to answer both questions at once, conflating proximate and ultimate explanations [Brush, 1978; Charnov, 1982]: an offspring sex ratio of $1: 1$ seems ensured by the independent assortment of the chromosomes during meiosis of sexual reproduction (GSD, genotypic sex determination).

This view came under challenge as evidence mounted that sexual outcome in many invertebrates is linked to environmental conditions [Korpelainen, 1990]. And it is not an overstatement to say that the discovery of temperature-dependent sex determination (TSD) in a reptile (Agama agama) [Charnier, 1966] came as a complete surprise. TSD was soon confirmed in multiple species of reptiles [Bull and Vogt, 1979] and concurrently, the first theories were asking the question: Why TSD and not GSD? James Bull and Eric Charnov established evolutionary theory of environmental sex determination (ESD) more generally and placed it within the domain of sex allocation theory, implicating the inescapable force of frequency-dependent selection on sex (see below) [Charnov and Bull, 1977; Bull, 1981b, 1983; Charnov, 1982]. This early theory built a foundation for most adaptive explanations of ESD. It also offered early evidence of neutral evolutionary pathways between GSD and TSD [Bull, 1981a]. Another decade passed before conceptual models began asking How? by synthesizing what was known of physiologi$\mathrm{cal}$ and molecular processes governing sexual outcome [Georges, 1989; Crews et al., 1994; Georges et al., 1994; Pieau, 1996; Pieau et al., 1999]. In the last 20 years, these long-standing theoretical questions of why and how have been accompanied by an explosion of theory into the population consequences of temperature-sensitive sex ratios, particularly under the threat of climatic warming [Mitchell et al., 2010; Saba et al., 2012; Boyle et al., 2014b; Blechschmidt et al., 2020].

Theory has touched every aspect of sex determination because of the fundamental importance of the sex ratio for both evolutionary biology and population dynamics. Indeed, within evolutionary theory, sex ratios are so central that there is an ambivalence regarding exactly what the "environment" is that impacts sex or sexual development. So broad is the remit of this theory, that hypotheses and conclusions can be applied equally to TSD [Bull, 1981b], size-dependent sexual development [Blackmore and Charnov, 1989], and sex change during an animal's life [Leigh et al., 1976]. Yet, from an empirical perspective, defining the exact environmental factor(s) driving sexual development - temperature, $\mathrm{pH}$, nutrient availability - is paramount. This creates some confusion in translating theoretical findings, which are formulated with a broad general focus, into implications for empirical systems, where there is typically a specific focus. Theoretical predictions that are relevant for TSD may not be apparent because they are framed in terms of size or a very general notion of "environment." Intriguingly, this theoretical ambiguity regarding "environment" may well-represent empirical reality if there are common proximal cellular processes that commit presumptive gonads to follow a male or female trajectory regardless of the environmental cue [Castelli et al., 2020].

"All models are wrong, but some are useful," goes the common aphorism. To delve into theory requires a willingness to set aside the messy and, in a sense, superfluous details of real life and focus on core biological features in the quest for fundamental truth. This is not really very different from empirical research, which must also narrow its scientific question and set aside potential messy complications. Theory may provide proof of concept, explore the boundaries of expectation, reveal counter-intuitive dynamics, or test sensitivities to unknown parameters. Some models aim to describe a particular species or system, while others are purposefully "species-vague" in the search for generality. Much of ESD theory begins by defining the environmental patches, then specifying how environmentally dependent sex ratios may arise (or not arise), though the specific approaches vary (Fig. 1). Luckily, predictions typically do not depend on which particular theoretical approach is used, though they do depend on model assumptions.

Here, we review what we have learned from theoretical examination of environmental influences on sex determination across multiple research domains. While the literature in these domains often remain separated, the fundamental concepts and implications are intricately interwoven, and great insight can be gained by considering them together. Our primary focus is what theory tells us about reptiles with TSD. However, we will consider all theory addressing environmental effects in organisms that develop permanently into a single sex early in life (gonochores), and occasionally stray even further. We begin with an account 


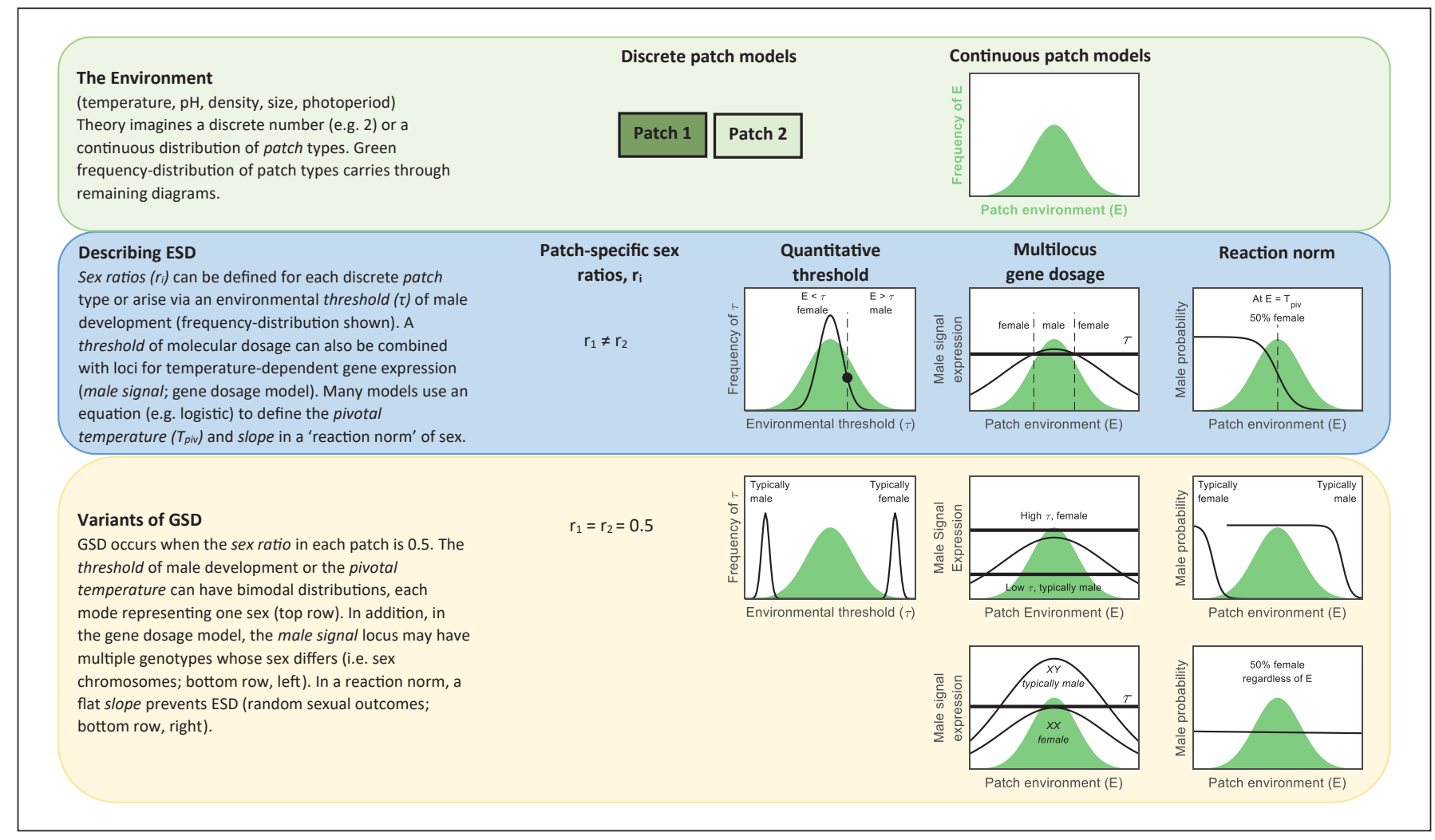

Fig. 1. Typical approaches used in theoretical models of environmental sex determination (ESD; though not exhaustive), identifying the key variables or parameters (italics).

of frequency-dependent selection as a central player in sex ratio evolution. We then overlay this underpinning process with the evolutionary dynamics and adaptive hypotheses of TSD, as well as the ecological and demographic consequences of sex determination. Finally, we finish with advances in theory regarding the underlying molecular mechanisms, how they have clarified evolutionary transitions between TSD and GSD, and the new insight this has provided into evolutionary and ecological theory.

\section{The Central Role of Frequency-Dependent Selection on Sex}

Frequency-dependent selection on sex is an inescapable force, and it is strong [Clarke, 1979; Bulmer and Bull, 1982]. It underpins most theory on sex ratios, including work on environmentally sensitive sex ratios. The effect of this selection is not always intuitive or easy to predict [e.g., Girondot et al., 1998; Uller et al., 2007; Harts et al., 2014 ], and that is why theoretical approaches to sex ratios are so useful and fun.

Theoretical Conclusions on Sexual

Development and the Environment
The issue is that female-biased sex ratios provide an advantage to populations because they allow populations to grow faster - the more females a population has, the more offspring the population produces. So, why do so many populations have a 1:1 sex ratio? This was a puzzle for early evolutionary biologists who were attempting to explain how individual-level selection could drive a group-level trait [Darwin, 1871, 1874; Düsing, 1884; Edwards, 1998]. Resolving the puzzle provided evolutionary biology with one of the most compelling arguments for the power of individual-level selection to outweigh grouplevel advantages. Because, as it turns out, while femalebiased sex ratios may be great for persistence of a population, they are rarely optimal for individuals.

The solution, often credited to Fisher [1930], is the underlying action of negative frequency-dependent selection on sex (Fig. 2). The logic of the argument is based on "inheritance symmetry." Because every individual has exactly one mother and one father, the offspring gene pool is split equally between mothers and fathers. If there are fewer males than females contributing to the offspring gene pool, each male gets a bigger slice of the gene pool 

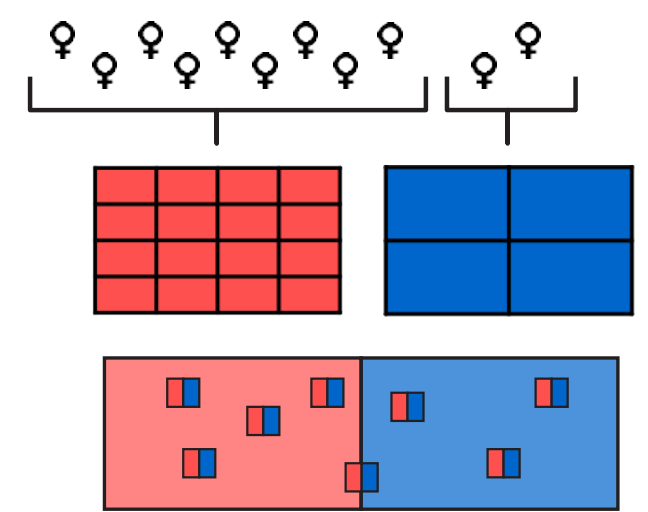

Step 3: Negative frequency-dependent selection Grandmother (e.g. nesting turtle)

Step 2: Rare sex advantage

Focal generation (e.g. embryo undergoing

sexual development)

Step 1: Inheritance symmetry

Offspring (e.g. future offspring that an individual

in the focal generation might produce)

\begin{abstract}
Frequency-dependent selection on sex moves the primary sex ratio towards the equilibrium (or evolutionarily stable) sex ratio. The primary sex ratio is typically defined as the sex ratio at conception. Under environmental sex determination, research is more often concerned with the sex ratio at hatching, assuming that mortality to hatching is not sex-biased. This is called the secondary sex ratio, population sex ratio or cohort sex ratio.
\end{abstract}

To understand frequency-dependent selection on sex, it helps to think about three generations:

Step 1: Inheritance symmetry -

First consider the youngest generation of offspring. In most species, every offspring (little squares) gets half of its genes from its mother (red) and half of its genes from its father (blue). Hence, in the offspring gene pool, $50 \%$ of the genes came from a male parent and $50 \%$ of the genes came from a female parent (big squares).

Step 2: Rare sex adventage -

Imagine there were 16 females and 4 males in the focal generation ( $80 \%$ females). Each female contributes $1 / 16^{\text {th }}$ of the $50 \%$ of 'mother genes' to the offspring generation. In contrast, each male contributes $1 / 4^{\text {th }}$ of the $50 \%$ of 'fathers genes' to the offspring generation. Having $12.5 \%$ of the genetic pie $(0.5 \times 0.25)$ via being a male is better than having $3 \%(0.5 \times 0.0625)$ via being a female.

Step 3: Negative frequency-dependent selection -

If one of the focal females had instead developed as a male, or if a grandmother of a female had instead produced a male, that individual would have quadrupled their genetic representation in the offspring generation. Thus, the rare-sex advantage creates negative frequency-dependent selection on sex.

Fig. 2. Frequency-dependent selection on sex underpins evolution of sex ratios.

pie than each female. There is thus an advantage to being the rare sex in a population. Under ESD, traits associated with embryonic development (e.g., thermal sensitivity) or maternal behavior (e.g., basking or oviposition behavior) that lead to investment in the rare sex (here, males) will be favored. In this way, individual-level selection drives the evolution of the primary sex ratio toward the evolutionary stable sex ratio, which is often (but not always) 1:1 (see Ultimate Explanations below). When neither sex is "rare," sex ratio variation becomes selectively neutral (i.e., frequency-dependent selection does not take effect [Bull and Charnov, 1988]).

Frequency-dependent selection is not directly specified in models. It arises and takes over whenever inheritance symmetry and relative fitness are accommodated in the modeling. Any trait that can evolve in the model will respond to it. What makes traits evolvable in theoretical models? Traits must (1) vary, such as via initial seeds of variation, mutation, migration, or otherwise assuming that (virtually) any trait value is possible (as in optimality models); and (2) be inherited. Thus, the speed, though rarely the eventual outcome, of evolutionary response is sensitive to model assumptions of mutation and heritability. When considering the implications of a particular model, it is important to identify whether or not evolution is operating. Predictions arising when evolution is limited may be highly relevant for populations of longlived individuals under environmental change, but they often do not agree with predictions arising if traits are sufficiently evolvable (i.e., the predictions are not "evolutionarily stable").
Schwanz/Georges 


\section{Ultimate Explanations of ESD}

The evolution of ESD (or TSD) is often viewed as a balance between opposing selective pressures, with selection for ESD being opposed by frequency-dependent selection against ESD when sex ratios become biased. While frequency-dependent selection can play this role, this view overlooks the critical role that it plays in shaping ESDrelated traits irrespective of whether ESD confers any fitness advantages. Thus, it is worth considering first how frequency-dependent selection shapes those traits linking environment to sex before turning to selection for ESD itself.

For ESD, environmental thresholds (e.g., pivotal temperature) and maternal oviposition behavior are likely targets of frequency-dependent selection, though models disagree on which one evolves more quickly [Morjan, 2003; Pen et al., 2010; Schwanz et al., 2013; Harts et al., 2014; Butka and Freedberg, 2018; Blechschmidt et al., 2020]. Effective heritability of pivotal temperature is thought to be low because interindividual variability, the fodder of natural selection, is typically only expressed across a relatively narrow range of temperatures experienced in the wild [Bull et al., 1982; Bulmer and Bull, 1982; Janzen, 1992; McGaugh and Janzen, 2011]. Despite this, theoretical models often demonstrate effective evolution of the pivotal temperature [e.g., Pen et al., 2010; Schwanz et al., 2013]. Moreover, there is empirical support for evolvability. Silverside minnows held at temperatures that induce a sex ratio bias consistently overproduce the rare sex in each successive generation and demonstrate rapid compensatory change (within $<10$ generations) in pivotal temperature [Conover and Van Voorhees, 1990; Conover et al., 1992].

If there is no pivotal temperature or oviposition behavior that provides an equilibrium sex ratio in each cohort (i.e., due to fluctuating of directionally changing environments), plasticity in these traits may evolve and moderate links between climate and sex. While not widely appreciated, the thresholds that define how sex responds to the environment (e.g., a pivotal temperature) are predicted to be highly plastic in response to the local availability of environmental patches [Charnov et al., 1978, 1981; Charnov, 1982; Blackmore and Charnov, 1989; Schwanz et al., 2010a]. In reptiles with TSD, plasticity in pivotal temperatures exists via the concomitant influence of hydric conditions, resource provisioning, and hormones on sexual development [Bowden et al., 2000; Elf, 2003; Warner et al., 2007; Radder et al., 2009]. However, few studies have asked whether TSD plasticity is linked to maintenance of

Theoretical Conclusions on Sexual

Development and the Environment an equilibrium sex ratio [Robert et al., 2003; Warner and Shine, 2007; Schwanz et al., 2010a].

If trait evolution or plasticity are not sufficient to balance sex ratios, frequency-dependent selection will indeed oppose the evolution and maintenance of ESD, leading to the evolution of shallower relationships between sex and environment or the complete loss of ESD (in favor of GSD or random sex determination, see Transitions between Sex-Determining Systems; Fig. 1) [Bull and Bulmer, 1989; Van Dooren and Leimar, 2003; Leimar et al., 2004; Schwanz and Proulx, 2008; Pen et al., 2010; Schwanz et al., 2010b; Grossen et al., 2011]. Here, silverside minnows again provide crucial empirical support for this evolutionary process, as some selection lines lost ESD after a few generations of exposure to temperatures inducing biased sex ratios [Conover et al., 1992]. Shallower relationships can also reflect greater genetic variance in environmental thresholds, the outcome of disruptive selection on the threshold [Bulmer and Bull, 1982; Leimar et al., 2004]. This greater genetic variance, in turn, allows populations to evolve more rapidly in response to selection [Bulmer and Bull, 1982; Hulin et al., 2009].

On the other hand, mixing among cohorts ameliorates the cost of variable primary sex ratios [Bull and Bulmer, 1989; Van Dooren and Leimar, 2003; Schwanz and Proulx, 2008; Harts et al., 2014]. Mixing occurs when (1) offspring from multiple populations migrate among populations to create shuffled adult breeding populations; or (2) offspring from multiple generations overlap in the adult breeding population (i.e., overlapping generations). It has the potential to equilibrate adult sex ratios [but see Butka and Freedberg, 2018]. This changes the scale upon which frequency-dependent selection acts because the primary sex ratio is inclusive of all cohorts that contribute to the adult mating pool (the "effective primary sex ratio"). Populations with high mixing require weaker selection for ESD to drive the origin and maintenance of ESD compared with populations with low mixing [Bull and Bulmer, 1989; Van Dooren and Leimar, 2003; Schwanz and Proulx, 2008]. As a result, ESD can be maintained evolutionarily in meta-populations and in long-lived species despite local or fluctuating biases in the primary sex ratio [Bull and Bulmer, 1989; Reinhold, 1996; Julliard, 2000; Van Dooren and Leimar, 2003; Schwanz and Proulx, 2008; Harts et al., 2014; Butka and Freedberg, 2018]. Indeed, TSD is more common among turtle species (typically long lifespans) compared to squamate species (typically short lifespans) [Sabath et al., 2016]. Moreover, these predictions, and the apparently easy transition between GSD and TSD (see section Transitions between Sex-De- 
Table 1. Summary of major theoretical findings relating to environmental sex determination

\begin{tabular}{lll}
\hline Major finding & Details & Citations \\
\hline Ultimate explanations &
\end{tabular}

Sex-specific impacts of the environment on lifetime fitness (differential fitness) selects for ESD
Broadly

Broady

Charnov and Bull, 1977, 1989a, b; Bull, 1981b; Charnov, 1982; Frank and Swingland, 1988; Bull and Charnov, 1989; Schwanz et al., 2006

Impacts of season of birth on growth and fertility drive differential fitness

Sex-differential juvenile survival is sufficient; it could arise from sex differences in the age of maturity

Sex-biased natal philopatry alone establishes sex-differential fitness

Under sex-differential fitness, the evolutionarily stable (or equilibrium) sex ratio is typically not 0.5

Common prediction: More of the sex produced under poor conditions

Warner et al., 2009; Pen et al., 2010

Schwanz et al., 2006, 2016

Reinhold, 1996, 1998; Julliard, 2000; Freedberg and Wade, 2001; Hulin and Guillon, 2007

Bull, 1981b; Bulmer and Bull, 1982; Frank and Swingland, 1988; Bull and Charnov, 1989; Charnov and Bull, 1989a, b

Fluctuating sex ratios across space or time, and the amount of mixing, influence the shape of the reaction norm, evolution of ESD traits, and loss of ESD

When "mixing" of cohorts occurs, weaker selection is needed for ESD to persist
Bulmer and Bull, 1982; Bull and Bulmer, 1989; Van Dooren and Leimar, 2003; Leimar et al., 2004; Schwanz and Proulx, 2008; Pen et al., 2010, Schwanz et al., 2010a;

Bull and Bulmer, 1989; Van Dooren and Leimar, 2003; Schwanz and Proulx, 2008 Harts et al., 2014

\section{Population dynamics}

Female-biased adult sex ratios provide greater population growth than male-biased adult sex ratios

Frequency-dependent selection should prevent primary sex ratios that deviate from the equilibrium

Cohort sex ratios will vary over space and time

Adult sex ratios may not reflect cohort sex ratios
Owing to local adaptation or evolution of plasticity in threshold traits

With no or little evolution considered

With robust evolution, mixing of cohorts precludes adaptations that prevent biased cohort sex ratios
Woodward and Murray, 1993; Girondot et al., 1998; Freedberg and Taylor, 2007; Mitchell et al., 2010; Boyle et al., 2014a, b; Harts et al., 2014; Butka and Freedberg, 2018

e.g., Bull, 1981b; Charnov, 1982; Bull and Charnov, 1988; Morjan, 2003; Schwanz et al., 2010a, 2013, 2020

Janzen, 1994; Freedberg and Wade, 2001; Hays et al., 2003; Freedberg and Taylor, 2007; Boyle et al., 2014a, b

Bull and Bulmer, 1989; Reinhold, 1996, 1998; Julliard, 2000; Van Dooren and Leimar, 2003; Hulin and Guillon, 2007; Schwanz and Proulx, 2008; Schwanz et al., 2010a; Harts et al., 2014; Butka and Freedberg, 2018

Owing to mixing of cohorts across space and time or to demographics such as sex-specific juvenile survival and age at maturity
Bull and Bulmer, 1989; Girondot and Pieau, 1993; Van Dooren and Leimar, 2003; Schwanz and Proulx, 2008; Schwanz et al., 2010a; Harts et al., 2014; Butka and Freedberg, 2018

Kallimanis, 2010; Boyle et al., 2014b, 2016; Freedberg and Taylor, 2007; but see Escobedo-Galvan et al., 2011

Janzen, 1994; Hawkes et al., 2007; Mitchell et al., 2008, 2010; Patino-Martinez et al., 2012; Saba et al., 2012; Hays et al., 2017
Biased sex ratios across populations shape species ranges and enhance colonization and range expansion

Climate change in natural populations of reptiles leads to more-biased sex ratios and negatively impacts population viability

\section{Mechanism}

Fluctuating temperatures tend to favor the sex developing at warmer temperatures

Multilocus gene dosage models can explain GSD, TSD and mixed systems
Aromatase and gonadal development can also be included in a model

Assume temperature-sensitive signal expression and a separate locus for a threshold
Georges, 1989; Georges et al., 1994, 2004, 2005; Delmas et al., 2008; Valenzuela et al., 2019

Pen et al., 2010; Grossen et al., 2011; Quinn et al., 2011; Schwanz et al., 2013, 2020 
Table 1 (continued)

\begin{tabular}{|c|c|c|}
\hline Major finding & Details & Citations \\
\hline $\begin{array}{l}\text { Models with temperature-sensitive enzyme } \\
\text { dynamics in a simple network demonstrate } \\
\text { bistability }\end{array}$ & & Yamaguchi and Iwasa, 2018; Verma et al., 2020 \\
\hline \multicolumn{3}{|l|}{ Evolutionary transitions } \\
\hline $\begin{array}{l}\text { Transitions from GSD to ESD occur easily } \\
\text { along a neutral path if only the homogametic } \\
\text { sex gains thermosensitivity }\end{array}$ & $\begin{array}{l}\text { This happens naturally under a gene dosage } \\
\text { model and directional environmental change }\end{array}$ & $\begin{array}{l}\text { Bull, 1981a, 1983; Pen et al., 2010; Grossen et al., 2011; } \\
\text { Quinn et al., 2011; Schwanz et al., 2013, 2020; Holleley et } \\
\text { al., } 2015\end{array}$ \\
\hline $\begin{array}{l}\text { Mixed systems of sex determination may be } \\
\text { stable }\end{array}$ & Without substantial evolution & $\begin{array}{l}\text { Holleley et al., 2015; Schwanz et al., 2020; but see Kuijper } \\
\text { and Pen, } 2014\end{array}$ \\
\hline $\begin{array}{l}\text { Mixed systems are typically transitory when } \\
\text { evolvability is robust }\end{array}$ & $\begin{array}{l}\text { With selection for TSD or when fluctuating/ } \\
\text { biased sex ratios select for loss of } \\
\text { thermosensitivity }\end{array}$ & $\begin{array}{l}\text { Bulmer and Bull, 1982; Van Dooren and Leimar, 2003; } \\
\text { Pen et al., 2010; Grossen et al., 2011; Schwanz et al., } 2013\end{array}$ \\
\hline
\end{tabular}

ESD, environmental sex determination; GSD, genotypic sex determination; TSD, temperature-dependent sex determination.

termining Systems), raise the proposition that ESD may be neutral (or nearly so) compared to GSD, particularly in long-lived animals [Bull, 1980; Girondot and Pieau, 1996; Janzen and Phillips, 2006].

On this foundation of sex ratio selection, evolutionary theory of ESD really hits its stride in formulating adaptive hypotheses for ESD. Here, we will focus on hypotheses that have received formal theoretical attention [for further reviews, see Bull, 1983; Ewert and Nelson, 1991; Janzen and Paukstis, 1991; Valenzuela, 2004; West, 2009]. The original hypothesis for the evolution of ESD, as well as most hypotheses that have followed since, relies on sexdifferential fitness as driving selection for ESD [Charnov and Bull, 1977]. When Charnov and Bull presented this hypothesis [Charnov and Bull, 1977, 1989a; Bull, 1981b; Charnov, 1982], they drew on recent developments in sex allocation theory and placed ESD in the sex allocation category of "when fitness varies," also known as conditional sex allocation [Charnov, 1982; West, 2009]. This set of hypotheses encompasses biologies as diverse as ESD, sequential hermaphroditism, and maternally controlled offspring sex ratios [Trivers and Willard, 1973; Charnov et al., 1978, 1981; Charnov, 1982; West, 2009]. They are connected conceptually by the singular idea that males and females differ in how fitness depends on a key aspect of the environment (e.g., body size, maternal resource provisioning). The hypothesis posits that ESD is favored when fitness in one sex depends more on developmental environment than does the fitness of the other sex or that the two sexes differ in optimal developmental environments. It depends on 2 key assumptions: (1) the

Theoretical Conclusions on Sexual Development and the Environment population contains developmental patches that vary in environmental conditions; and (2) individuals cannot choose the environment in which they develop. Moreover, it is often assumed that mating is random with respect to patch of birth. Thus, most models of this hypothesis imagine patches at a fine scale in a highly mixed, unstructured population - such as shaded or open nests on a nesting beach.

The hypothesis is intuitively appealing and is well-supported by numerous theoretical studies. Sex differences in lifetime fitness or fertility/fecundity across environments will lead to the adaptive evolution of ESD (Table 1). Moreover, the equilibrium sex ratio is predicted to be biased toward the sex that is produced under "poor conditions" (not 1:1 sex ratio) [Bull, 1981b; Bulmer and Bull, 1982; Frank and Swingland, 1988; Bull and Charnov, 1989; Charnov and Bull, 1989a, b]. The hypothesis also accommodates a plethora of biological situations that could create sex-differential fitness [e.g., Shine, 1999; Schwanz et al., 2016]. Thus, the hypothesis provides fundamental basis and vision as an over-arching explanation for the occurrence of ESD across diverse taxa with diverse biologies. However, this diversity and flexibility is also challenging when it comes to testing the hypothesis empirically. After all, it is difficult to measure "lifetime fitness" directly, and there are so many ways that sex-differential fitness may arise [Shine, 1999; Schwanz et al., 2016]. Moreover, there has been skepticism as to how differential fitness might arise for very long-lived species like sea turtles and crocodilians, where it seems like accrual of fitness across a reproductive life happens many, many 
years after the developmental environment was experienced [West, 2009].

In response, theoreticians and empiricists alike have embraced the opportunity to hypothesize and test biological drivers of differential fitness. Three hypotheses have emerged as the strongest contenders. The first has empirical support in taxonomically diverse species: the developmental environment predicts how long a new offspring has to grow before the growing season ends, and size matters more for fertility of one sex versus the other [Conover, 1984; Warner and Shine, 2008; Warner et al., 2009; Pen et al., 2010]. This hypothesis has testable predictions: (1) sex ratios are seasonal, (2) season of birth impacts growth and size, and (3) maturity or reproductive success depends on size in a different manner for males and females. Moreover, across populations, we would predict that the incidence of differential fitness and selection for ESD are maximized at intermediately long growing seasons. Seasons that are too short do not create variation in growth and size, but seasons that are too long level the playing field [Conover and Heins, 1987; Conover, 2004; Pen et al., 2010]. The hypothesis is compelling for species that mature early, where 1-2 months of extra growth is a real advantage; however, it is more difficult to see operating in long-lived species like turtles and crocodilians.

The second contender proposes that differential fitness in juvenile survival alone is sufficient to drive conditional sex allocation, including ESD [Schwanz et al., 2006]. Differential fertility between males and females is not necessary to select for ESD. This idea has been a major advance in understanding ESD in long-lived species, though it applies to any life history. Recently, Schwanz et al. [2016] proposed a novel hypothesis for how differential survival to maturity can arise. The "survival to maturity" hypothesis [Schwanz et al., 2016] posits that 2 very simple and credible biological features combine to create differential fitness: (1) the survival rate (e.g., annually) of males and females is equally impacted by developmental environment, and (2) males mature at a different age than females. Whichever sex matures later accrues a greater survival disadvantage from the "poor" environment than does the sex that matures earlier, thus giving rise to differential survival and selection for ESD. This sex should develop in good conditions. According to this hypothesis, the occurrence of ESD could be explained by greater sex differences in the age of maturity, a prediction which has been met with some empirical support across reptile species [Schwanz et al., 2016; Bókony et al., 2019].
In contrast to these hypotheses regarding unstructured populations, theoretical models in the third category have taken a more structured view to examine the adaptive evolution of ESD. They have focused on one key element of population structure: daughters are more likely than sons to breed in the same type of patch they themselves developed in. This could arise via sex-biased dispersal across a large spatial scale, such as among nesting beaches of different thermal characteristics, or via cultural inheritance of fine-scale nest site selection within a single breeding location. In this situation, ESD may evolve as long as nesting patches differ in quality and natal philopatry is sex-specific [Reinhold, 1998; Julliard, 2000; Freedberg and Wade, 2001; Hulin and Guillon, 2007]. Differential fitness emerges simply because the reproductive success of daughters is tied to their developmental environment owing to philopatry. In contrast, the reproductive success of males is not tied to their developmental environment because they shuffle around when choosing their breeding site (or mating partner). Another way this has been phrased is that ESD allows production of the philopatric sex in good habitats and production of the dispersive sex in poor habitats [Julliard, 2000]. The models differ according to whether they predict ESD is most likely at the greatest philopatry [Freedberg and Wade, 2001] or at lower levels of philopatry [Julliard, 2000; Hulin and Guillon, 2007], an important distinction for empirical tests. This hypothesis has yet to be embraced as an explanation for the occurrence of TSD versus GSD because many species with GSD are also likely to have female-biased natal philopatry. Certainly, the hypothesis needs more empirical work, as well as theoretical exploration.

\section{Biased Sex Ratios and Population Dynamics}

Despite the counterbalancing and strong force of frequency-dependent selection, many examples of biased sex ratios exist in wild species with TSD, both among populations or within a single population across time [Bull and Charnov, 1988, 1989; Freedberg and Wade, 2001; Girondot et al., 2004; Schwanz et al., 2010b; Witt et al., 2010; Escobedo-Galvan et al., 2011]. Given that sex ratios are an important population demographic, what does this mean for population viability, meta-population dynamics across a species' range, and the response to directional climate change across time? Most simply, when the density of adult males or females within in a population is sufficiently low, the population will go extinct [e.g., Berec 
et al., 2001]. In particular, populations are highly sensitive to the number of breeding females ("female demographic dominance"), assuming fecundity is not strongly dependent on male abundance (i.e., polygyny). Thus, as long as primary sex ratios translate into adult sex ratios, populations are predicted to have increased productivity when they are female-biased [Girondot et al., 2004; Mitchell et al., 2010; Saba et al., 2012; Boyle et al., 2014a; Harts et al., 2014; Butka and Freedberg, 2018]. Production of female-biased sex ratios allows populations (e.g., TSD populations) to grow more quickly than populations constrained to a 1:1 sex ratio and to outcompete them (e.g., GSD populations) [Woodward and Murray, 1993; Freedberg and Taylor, 2007; Boyle et al., 2014a].

While these predictions seem straightforward, biased sex ratios and their population consequences are unlikely to persist in isolated populations that have time and capacity to evolve. The population-level advantage of a female-biased sex ratio is quickly subverted by frequencydependent selection, which returns the sex ratio to its equilibrium [Girondot et al., 1998], as described in the previous sections. So, then what explains why many populations of TSD species have biased cohort sex ratios? And what does this mean for their dynamics? The answer relies on appreciating that populations are unlikely to be isolated.

When population dynamics are extended to a metapopulation with migration (i.e., mixing), interesting dynamics arise and allow population sex ratios to remain biased. Biased population sex ratios persist despite evolution because local adaptation is prevented by migration and because cohort mixing reduces adult sex ratio biases [Reinhold, 1996, 1998; Julliard, 2000; Van Dooren and Leimar, 2003; Hulin and Guillon, 2007; Harts et al., 2014; Butka and Freedberg, 2018]. Perversely, female-biased populations, with their high productivity, dominate evolutionary adaptation to temperature and send genes adapted to female-producing habitats into male-producing habitats, further sabotaging growth in these metapopulation sinks [Harts et al., 2014; Butka and Freedberg, 2018]. Furthermore, just as mixing reduces local adaptation, it also obviates the need for plasticity. Plasticity is predicted to be strong in systems with low mixing (e.g., short-lived animals) but weak in systems with high mixing (e.g., long-lived animals) [Schwanz et al., 2010a]. Thus, theory tells us that in long-lived, widely dispersing animals, there is little selection for cohort-level maintenance of equilibrium sex ratios and large genetical impediments against it. As a result, primary sex ratios are likely to be at least somewhat related to local environmen-

Theoretical Conclusions on Sexual Development and the Environment tal conditions in these species [Hulin et al., 2009]. We should expect that the same conclusions apply to GSD species that experience thermolability in sexual differentiation.

These dynamics can play out across a species' range. If extreme developmental temperatures occur at the edges of the species' range, then the range edges will be shaped by sex ratio biases, with the range centered around female-producing habitats [Boyle et al., 2014b]. In contrast, the range of species with GSD is governed by temperature-driven offspring mortality [Boyle et al., 2014a, b]. Under a warming climate, range change has the potential to happen more quickly in TSD species than GSD species (assuming the cool range edge is male-biased), because female abundance increases in areas where populations have never been limited by low viability [Kallimanis, 2010; Boyle et al., 2016]. However, the limited data on population-level variation in primary sex ratios across species' ranges show poor mapping between sex ratios and ambient temperatures owing to population variation in nesting behavior and substrate physical properties [Hays et al., 2003; Witt et al., 2010; Escobedo-Galvan et al. 2011; Patino-Martinez et al., 2012]. These empirical findings suggest that meta-population models with more idiosyncratic geographic structure in sex ratios will enhance insight into natural systems.

These simple predictions provide a solid baseline expectation, but do they apply to real populations and species subject to additional demographic complications? For example, theory tells us that the benefits that arise from female-biased populations are diminished when female fecundity is sensitive to male limitation or when hatching success declines at female-producing temperatures [Saba et al., 2012; Boyle et al., 2014a; Hays et al., 2017]. Moreover, adult sex ratios are more strongly influenced by sex differences in age at maturity and annual survival than they are by the primary sex ratio [Girondot and Pieau, 1993; Girondot et al., 2004], yet few theoretical studies have examined the sensitivity of population dynamics to these demographic effects [see Mitchell et al., 2010; Freedberg and Debenport, 2014]. For several species of turtles facing climate change, known links between air temperature and the cohort sex ratio or average nest temperatures have led to predictions of increasingly female-biased sex ratios [Janzen, 1994; Hays et al., 2003; Hawkes et al., 2007; Patino-Martinez et al., 2012; Saba et al., 2012]. For the tuatara, microclimate modeling predicts warming soil (nest) temperatures, increasingly male-biased sex ratios, and reduced population viability under climatic warming [Mitchell et al., 2008, 2010]. In 
contrast, for sea turtle populations living at extreme developmental temperatures, the biggest risk of rising temperatures is the decline in hatching success [Saba et al., 2012; Hays et al., 2017]. While the consequences and dynamics of biased population sex ratios have been poorly explored in empirical systems, climatic warming is sadly destined to provide us with new data to test theoretical predictions in TSD species.

\section{Mechanisms of ESD}

Whereas the evolutionary and ecological implications of ESD have been examined extensively, we know remarkably little about how developmental (e.g., gene regulatory) networks establish the fundamental dichotomy of sexual phenotypes (i.e., bistability). This is particularly intriguing in the face of inconstant developmental conditions typical of most TSD (or ESD) and GSD species. In species with TSD, there is a protracted thermosensitive period (typically extending across the middle third of development) during which sex is responsive to temperature. Differentiation of gonadal tissue (into male or female) during this period is subject to seasonal climatic trends, changes in weather, and other stochastic events. Thus, hidden in the long-appreciated phenomenon of sex determination are 2 striking implications that have never been explored theoretically: (1) species with ESD have developmental networks that allow bistable outcomes despite fluctuations in the environmental cue; and (2) species with GSD have networks that can override the temperature sensitivity of molecular interactions.

Sex determination has long been viewed as dependent on the dosage of a key protein - whether it is aromatase or estrogen, a major sex-determining factor, or a temperature-sensitive gene within the regulatory network [Crews et al., 1994; Pieau, 1996; Pieau et al., 1999; Quinn et al., 2011]. For reptiles with TSD, this view is derived, in part, from evidence that exogenous hormones can override the influence of temperature in determining sex in a dosagedependent fashion [Crews et al., 1994]. Thus, when dosage of the key signal exceeds some threshold, sex becomes committed to male or female [Uller and Helanterä, 2011; Beukeboom and Perrin, 2014]. In addition, dosage exposure must also account for temperature-specific rates of development for the following reason. When temperatures fluctuate, embryos undergo a greater proportion of development at warmer temperatures than at cooler, and spend more of their development exposed to molecular signals present at warm temperatures. Therefore, off- spring sex ratios are influenced not just by mean temperature, but by daily fluctuations in temperature [Georges, 1989; Georges et al., 1994]. Accounting for this effect by adjusting the mean temperature (the constant temperature equivalent), using measures of accumulated temperature (weighted cumulative temperature units), or incorporating gonadal growth rates and aromatase activity demonstrably improves the accuracy in predicting empirical sex ratios [Georges, 1989; Georges et al., 1994, 2004, 2005; Delmas et al., 2008; Valenzuela et al., 2019]. Thus, a basic mechanistic understanding of the developmental processes during sex determination has been gained through the marriage of empirical data and conceptual models.

This dosage-threshold view has been generalized across species and expanded to incorporate GSD systems in a single, quasi-mechanistic theory of sex determination (the multilocus dosage model; Fig. 1) [Grossen et al., 2011; Quinn et al., 2011; Pezaro et al., 2016]. In this hypothesis, dosage of gene expression (e.g., a "male signal") depends on temperature. A separate gene locus controls the threshold level of this signal required to commit to one sexual pathway or the other. GSD exists when (1) the locus of sexual "signal" has multiple genotypes with very different quantitative signal expression, and (2) the threshold lies in between peak expression for 2 of the genotypes. Becoming male or female, then, depends on an individual's genotype in wild populations, and there is no detectable role of temperature over the range of natural developmental temperatures. For such a species, any evidence of TSD is a laboratory artifact. In contrast, TSD exists when there is only one genotype at the signal locus and its expression level falls above or below the threshold depending on temperature (TSD may also occur with many genotypes that generate quantitative variation in signal expression) [Pezaro et al., 2016]. If the relationship between the signal and temperature is roughly bellshaped (with an intermediate temperature of peak expression) [Quinn et al., 2011], the model accommodates the 3 forms of TSD reaction norms (i.e., male-female, female-male, female-male/mixed-female) [Ewert and Nelson, 1991; Janzen and Paukstis, 1991; Quinn et al., 2011]. The diversity arises based on which side(s) of the bellshaped curve of signal expression a population experiences. The gene dosage model additionally encompasses a diversity of systems of mixed genotypic and environmental influence on sexual phenotype.

Gene dosage models have already advanced evolutionary views on sex-determining mechanisms (see section Transitions between Sex-Determining Systems), but they do not explain 2 crucial features of TSD: what creates the 
threshold (i.e., bistability) and what makes the signal temperature-sensitive? These questions may be answered by a theoretical systems biology approach. Systems biology can distil the complexity of developmental networks into functional design principles (e.g., nodes and motifs) using mathematical models [Alon, 2006]. For example, positive feedback loops between genes can convert graded input (e.g., temperature cues) into bistable output (e.g., testis vs. ovary) and induce "lock-in" memory. Feed-forward loops create protection against transient loss of signal, which could be crucial under fluctuating environments [Alon, 2006]. Are network structures such as these important in creating temperature sensitivity, thresholds, and bistability in sex-determining networks?

Bistability of sexual development likely relies on the resolution of mutual inhibition (a double-negative feedback loop) between genes of a testis-development motif (centered around Sox9 in mammals) and genes of an ovary-development motif (centered around Foxl2) [Sánchez and Chaouiya, 2016; Capel, 2018; Sánchez and Chaouiya, 2018]. Recent systems biology models of TSD have focused on a simplified network incorporating only positive feedback between estrogen and aromatase (e.g., via the Foxl2 motif) and inhibition of aromatase expression by testosterone. When the production rates of aromatase or estradiol are more sensitive to temperature than are their decay rates (or vice versa), the ratio of estrogen to testosterone (and likely sexual outcomes) develops a switch-like relationship with temperature [Yamaguchi and Iwasa, 2018; Verma et al., 2020].

The proximal causes of temperature sensitivity may also be revealed by examining network dynamics. At the 2 extremes of proximal explanation lie (1) the concept of a single temperature-sensitive master sex gene yielding an accumulative dose response and (2) the concept of a parliamentary model whereby there is a system-wide shift of regulation of sexual development through the action of temperature on multiple genes (with hysteresis) [Crews and Bull, 2009; Georges et al., 2010]. Evidence is mounting that thermosensitivity involves an interaction between ubiquitous biochemical processes of calcium ion concentration and reduction-oxidation processes [Castelli et al., 2020], and thermosensitive genes (e.g., CLK4) [Haltenhof et al., 2020] involved in transducing the environmental signal. This then influences downstream signaling pathways that trigger a cascade of epigenetic and regulatory processes to activate key sex genes [Deveson et al., 2017; Ge et al., 2017, 2018; Weber et al., 2020]. Thus, no longer are we considering solely a single temperaturesensitive gene or a parliamentary model driving sex de-

Theoretical Conclusions on Sexual Development and the Environment termination, but rather a "mini-parliamentary" model involving a small number of key players, biochemical and genetic [Uller and Helanterä, 2011]. While there have been several recent advances in the systems biology view of sex determination, much work is still needed to create and refine mechanistic theory in tandem with empirical testing.

\section{Transitions between Sex-Determining Systems}

Chromosomes are often conserved over many millions of years. Yet the evolutionary history of some groups (e.g., reptiles, amphibians) shows a marked lability in sex determination function, with different autosomes being recruited as sex chromosomes, or the lack of apparent sex chromosomes under ESD. The distribution of these "traits" suggests frequent de novo evolution of the mechanism of sex determination and indeed frequent reversals [Sarre et al., 2011]. Clearly there is a dynamism to the evolution of sex-determining mechanisms that requires explanation. Theory has much to contribute to this debate. It all starts with sensitivity of sexual development to temperature (see section Mechanism of ESD) [Whiteley et al., present volume] and the resulting perturbation of GSD [Georges et al., 2010; Grossen et al., 2011; Sarre et al., 2011].

There are neutral pathways between GSD and TSD, and between male and female heterogamety [Bull, 1981a, 1983; Grossen et al., 2011; Schwanz et al., 2013, 2020; Holleley et al., 2015]. Transitions from GSD to TSD are hypothesized to occur primarily through the acquisition of thermosensitivity in the homogametic sex (XX or ZZ, socalled "sex reversal"), thereby avoiding the production of potentially lethal or sublethal YY or WW chromosomal combinations [Bull, 1981a, 1983]. If this sex reversal occurs in a sufficient number of homogametic individuals (typically at least 50\%), the population will experience a rapid elimination of the $\mathrm{Y}$ or $\mathrm{W}$ chromosome under frequency-dependent selection [Bull, 1981a; Hurley et al., 2004; Grossen et al., 2011; Schwanz et al., 2020]. This occurs because, for example, XY males have to compete with XX males to mate with XX females, so the proportion of the XY genotype decreases over time. Loss of the $\mathrm{Y}$ or W chromosome equates to loss of GSD. Given the difficulty of reversing this loss, TSD is often viewed as an evolutionary trap.

This may seem, at first glance, like an improbable scenario. But it is actually not at all improbable, owing to 2 proposed features of sex-determining mechanisms. These 
2 features are assumed in the gene-dosage model of sex determination (see Mechanisms of ESD) [Quinn et al., 2011], though they are not exclusive to that model. First, thermosensitivity does not require major structural change in the genes involved in sex determination. Changes in the levels of gene expression relative to threshold levels required to become male (or female) are sufficient to drive transitions. Given the fundamentally temperature-sensitive nature of gene expression, this can readily occur with unusually hot or cold developmental temperatures [Quinn et al., 2011; Schwanz et al., 2013, 2020]. Second, under changes to any parameter of the gene-dosage model that causes genotype-phenotype incongruity (e.g., developmental temperatures, gene expression levels, or threshold traits), only one genotype is initially impacted. Thus, the hypothesized difference in thermosensitivity between heterogametic and homogametic genotypes originally proposed [Bull, 1981a] is assured under the gene-dosage model. Supporting the theoretical models, in 2 well-studied GSD reptile species, extreme temperatures impact sexual development in only homogametic individuals [Holleley et al., 2016].

While this pathway is neutral and there is a theoretical continuum of genotypic and environmental influences on a mechanistic level, are points on the pathway evolutionarily stable? Recent studies have suggested that mixed systems can persist when less than $50 \%$ of the homogametic sex is reversed [Grossen et al., 2011; Schwanz et al., 2013, 2020; Holleley et al., 2015]. Thus, thermolability of sex determination may be achieved without the complete loss of ancestral sex chromosomes, the $\mathrm{Y}$ or $\mathrm{W}$ remaining in the population at low and cryptic levels (assisted by dispersal) [Schwanz et al., 2020], and available to reemerge as the dominant influence on sex determination. In addition, mixed systems of sex determination can arise if sex reversal occurs in the heterogametic sex (e.g., XY females) or if there is parent-offspring conflict over optimal sex ratio [Hurley et al., 2004; Cotton and Wedekind, 2009; Grossen et al., 2011; Schwanz et al., 2013; Kuijper and Pen, 2014]. In these scenarios, thermolability is potentially transitory, and not an evolutionary trap.

In many transition models considered above, however, evolution is blunted. In contrast, when there is selection for TSD (via differential fitness), sex-determining systems move quickly from GSD to TSD without stopping in between, and TSD is more evolutionarily stable than a mixed system [Pen et al., 2010; Schwanz et al., 2013; but see Kuijper and Pen, 2014]. Analogously, in the absence of selection for TSD, selection against thermosensitivity may arise and draw systems back to GSD [Pen et al., 2010; Grossen et al., 2011; Schwanz et al., 2020]. This typically occurs when sex ratios become biased (under fluctuating or extreme temperatures) and frequencydependent selection acts on heritable variation in temperature sensitivity. Indeed, evolutionary loss of temperature sensitivity could be a more likely outcome than TSD when sex reversal occurs [Grossen et al., 2011]. Empirical tests of these predicted evolutionary dynamics are lacking.

This process of perturbation of and reversion to GSD may explain the evolutionary lability of sex chromosomes. In systems with thermolability (mixed systems or TSD), frequency-dependent selection may select for novel genetic elements to gain control of sex determination, thus causing the transition from TSD or an ancestral form of GSD to a derived form of GSD (as likely observed in silverside minnows) [Conover et al., 1992; Pen et al., 2010; Grossen et al., 2011]. This may arise via disruptive selection on the threshold locus, leading to the evolution of a bimodal distribution of threshold temperatures (Fig. 1) [Bulmer and Bull, 1982; Van Dooren and Leimar, 2003; Pen et al., 2010]. It may also occur via novel alleles at loci of major effect [Grossen et al., 2011], thus potentially establishing a new sex chromosome pair. This process of sex chromosome turnover via thermolability could also work in tandem with other selective forces that favor sex chromosome establishment (e.g., parent-offspring conflict, sexually antagonistic selection) [Rice, 1987; Uller et al., 2007; Blaser et al., 2011; Beukeboom and Perrin, 2014; Kuijper and Pen, 2014].

\section{Conclusions}

ESD theory began in earnest 40 years ago with the question Why? What is most striking about our modern understanding of the ultimate explanations for ESD is the persistence and dominance of the idea of differential fitness between males and females as a function of developmental environment. At the same time, consideration of population structure and "mixing" of cohorts highlights the inextricable nature of the evolutionary and ecological dynamics of ESD. They involve complex feedbacks that allow or even favor sex ratios that are biased at the cohort level. Thus, there is no need to invoke anything more (or less) complicated than individual-level selection to explain why primary sex ratios vary across space and time. We argue that theoretical examination of mechanisms of sex determination (particularly thermolability) provides insight into not just developmental biology but into the
18

Sex Dev 2021;15:7-22

DOI: $10.1159 / 00051522$
Schwanz/Georges 
evolution of ESD as well. Recent dosage models and network models of sexual development have advanced our understanding of the proximal links between GSD and TSD. They have also demonstrated how easy it is to transition evolutionarily between GSD and TSD. This raises the possibility that transitions can be driven in a nonadaptive fashion by changes in climate or by range expansion to new climates. It simultaneously vindicates adaptive hypotheses that assume little to no constraint in the origin of ESD. Under ESD, there is a complex interrelatedness of population structure, selection, demography, evolutionary transitions, and mechanism. It is the challenge in searching for simple underlying explanations for this complexity and the joy of discovering unanticipated outcomes that provides such great opportunity in theoretical work.

We highlight several avenues for advancing theoretical research:

Creating network models that explain the diversity of sex-determining mechanisms. Can gene regulatory networks represent GSD, TSD or mixed systems with only minor modification? Can simple motifs of gene regulatory networks create bistability (male vs. female) under fluctuating environments? How can temperature sensitivity in gene regulatory networks arise from many or few genes?

Determining the evolutionary stability of mixed systems. Models addressing transitions among sex-determining mechanisms arrive at different conclusions regarding the evolutionary stability of systems of mixed sex determination. Potentially, mixed systems can persist, but we need a better theoretical understanding of their evolutionary stability under different model assumptions, such as forces of selection, evolvability of traits, mechanistic processes, and environmental variation.

Examining the sensitivity of population dynamics to demographic processes that may apply concomitantly with sex ratio biases. When considering the ecological (and evolutionary) consequences of thermolability, there are several other demographic features that likely play a large role. These include (temperature-sensitive) offspring viability, sex-specific survival, and different ages of maturity. We know very little about how readily they overwhelm the impact of biased sex ratios.

The likelihood and speed of evolutionary response of different ESD-related traits, particularly under environmental change. A question such as Can evolution of nesting behavior save a TSD population from climate change? is difficult to address without sufficient knowledge of natural heritabilities, mutation rates, migration rates, etc. to accurately predict the speed of evolutionary response. Given our limited empirical knowledge in these areas, theory can offer answers by examining the sensitivity of trait evolution to different assumed values of these parameters.

Understanding how evolution of ESD within structured (meta)populations interacts with adaptation. In order to understand eco-evolutionary feedbacks within ESD more clearly and to tease apart unique predictions for different adaptive hypotheses of ESD, models are needed that vary in their assumptions of population structure (e.g., dispersal) and selective pressures for ESD.

\section{Acknowledgement}

We thank the editors of the special issue for the invitation to contribute this review. The paper was improved by comments from Eric Charnov, Claudia Crowther, Phil Pearson, Rebecca Raynal, Tobias Uller, Nicole Valenzuela, and 2 anonymous reviewers.

\section{Conflict of Interest Statement}

The authors confirm that there are no known conflicts of interest associated with this publication, and there has been no significant financial support for this work that could have influenced its outcome.

\section{Funding Sources}

This project was funded by a Discovery Grant from the Australian Research Council (DP170101147) awarded to A.G. (lead), L.E.S., Clare E. Holleley, Janine Deakin, Tariq Ezaz, Stephen Sarre, Paul Waters, and Jennifer Marshall Graves.

\section{Author Contributions}

L.E.S. performed the primary review of theoretical research and led the writing of the review. A.G. provided substantial written and intellectual contribution. 


\section{References}

Alon U. An Introduction to Systems Biology: Design Principles of Biological Circuits. Boca Raton: Chapman and Hall; 2006.

Arbuthnott J. An argument for divine providence, taken from the constant regularity observ'd in the births of both sexes. Philos T R Soc Lond. 1710;27:186-90.

Berec L, Boukal DS, Berec M. Linking the Allee Effect, sexual reproduction, and temperaturedependent sex determination via spatial dynamics. Am Nat. 2001;157(2):217-30.

Beukeboom LW, Perrin N: The Evolution of Sex Determination. Oxford: Oxford University Press; 2014

Blackmore MS, Charnov EL. Adaptive variation in environmental sex determination in a nematode. Am Nat. 1989;134(5):817-23.

Blaser O, Neuenschwander S, Perrin N. On the maintenance of sex chromosome polymorphism by sex-antagonistic selection. Am Nat. 2011;178(4):515-24.

Blechschmidt J, Wittmann MJ, Blüml C. Climate Change and Green Sea Turtle Sex Ratio-Preventing Possible Extinction. Genes. 2020; 11(5):588.

Bókony V, Milne G, Pipoly I, Székely T, Liker A. Sex ratios and bimaturism differ between temperature-dependent and genetic sex-determination systems in reptiles. BMC Evol Biol. 2019;19(1):57.

Bowden RM, Ewert MA, Nelson CE. Environmental sex determination in a reptile varies seasonally and with yolk hormones. Proc Biol Sci. 2000;267(1454):1745-9.

Boyle M, Hone J, Schwanz LE, Georges A. Under what conditions do climate-driven sex ratios enhance versus diminish population persistence?. Ecol Evol. 2014a;4(23):4522-33.

Boyle M, Schwanz LE, Hone J, Georges A. How do climate-linked sex ratios and dispersal limit range boundaries?. BMC Ecol. 2014b;14:19.

Boyle M, Schwanz L, Hone J, Georges A. Dispersal and climate warming determine range shift in model reptile populations. Ecol Model. 2016; 328:34-43.

Brush S. Nettie M. Stevens and the discovery of sex determination by chromosomes. Isis. 1978;69(247):163-72.

Bull JJ. Sex determination in reptiles.Q Rev Biol. 1980;55(1):3-21.

Bull JJ. Evolution of environmental sex determination from genotypic sex determination. Heredity. 1981a;47(2):173-84.

Bull JJ. Sex ratio evolution when fitness varies. Heredity. 1981b;46(1):9-26.

Bull JJ. Evolution of Sex Determining Mechanisms. Menlo Park: The Benjamin/Cummings Publishing Company, Inc.; 1983.

Bull JJ, Bulmer MG. Longevity enhances selection of environmental sex determination. Heredity (Edinb). 1989;63(Pt 3):315-20.

Bull JJ, Charnov EL. How fundamental are Fisherian sex ratios?. Oxford Surv Evol Biol. 1988; 5:96-135
Bull JJ, Charnov EL. Enigmatic reptilian sex ratios. Evolution. 1989;43(7):1561-6.

Bull JJ, Vogt RC. Temperature-dependent sex determination in turtles. Science. 1979; 206(4423):1186-8.

Bull JJ, Vogt RC, Bulmer MG. Heritability of sex ratio in turtles with environmental sex determination. Evolution. 1982;36(2):333-41.

Bulmer MG, Bull JJ. Models of polygenic sex determination and sex-ratio control. Evolution. 1982;36:13-26.

Butka EG, Freedberg S. Population structure leads to male-biased population sex ratios under environmental sex determination. Evolution. 2019;73(1):99-110.

Capel B. Vertebrate sex determination: evolutionary plasticity of a fundamental switch. Nat Rev Genet. 2018;18:675-89.

Castelli MA, Whiteley SL, Georges A, Holleley CE. Cellular calcium and redox regulation: the mediator of vertebrate environmental sex determination?. Biol Rev Camb Philos Soc. 2020;95(3):680-95.

Charnier M. Action de la temperature sur la sexratio chez I'embryon d'Agama agama (Agamidae, Lacertilien). C R Sc Biol Paris. 1966;160: 620-2.

Charnov EL. The Theory of Sex Allocation. Princeton: Princeton University Press; 1982.

Charnov EL, Bull JJ. When is sex environmentally determined?. Nature. 1977;266:828-30.

Charnov EL, Bull JJ. Non-fisherian sex-ratios with sex change and environmental sex determination. Nature. 1989a;338:148-50.

Charnov EL, Bull JJ. The primary sex ratio under environmental sex determination. J Theor Biol. 1989b;139(4):431-6.

Charnov EL, Gotshall DW, Robinson JG. Sex ratio: adaptive response to population fluctuations in pandalid shrimp. Science. 1978; 200(4338):204-6

Charnov EL, Los-den Hartogh RL, Jones WT, van den Assem J. Sex ratio evolution in a variable environment. Nature. 1981;289(5793):27-33.

Clarke BC. The evolution of genetic diversity. Proc R Soc Lond B Biol Sci. 1979;205(1161): 453-74.

Conover DO. Adaptive Significance of Temperature-Dependent Sex Determination in a Fish. Am Nat. 1984;123(3):297-313.

Conover DO: Temperature-dependent sex determination in fishes. In: Valenzuela N, Lance V, editors: Temperature-dependent sex determination. Washington: Smithsonian Institution Press; 2004. p. 11-20.

Conover DO, Heins SW. Adaptive variation in environmental and genetic sex determination in a fish. Nature. 1987;326(6112):496-8

Conover DO, Van Voorhees DA. Evolution of a balanced sex ratio by frequency-dependent selection in a fish. Science. 1990;250(4987): 1556-8.
Conover DO, Van Voorhees DA, Ehtisham A. Sex ratio selection and the evolution of environmental sex determination in laboratory populations of Menidia menidia. Evolution. 1992; 46(6):1722-30

Cotton S, Wedekind C. Population consequences of environmental sex reversal. Conserv Biol. 2009;23(1):196-206.

Crews D, Bull JJ. Mode and tempo in environmental sex determination in vertebrates. Semin Cell Dev Biol. 2009;20(3):251-5.

Crews D, Bergeron JM, Bull JJ, Flores D, Tousignant A, Skipper JK, et al. Temperature-dependent sex determination in reptiles: proximate mechanisms, ultimate outcomes, and practical applications. Dev Genet. 1994;15(3):297312.

Darwin C. The descent of man and selection in relation to sex. London: John Murray; 1871.

Darwin C. The descent of man and selection in relation to sex, 2nd ed. London: John Murray; 1874.

Delmas V, Prevot-Julliard AC, Pieau C, Girondot M. A mechanistic model of temperature-dependent sex determination in a chelonian: the European pond turtle. Funct Ecol. 2008;22: 84-93.

Deveson IW, Holleley CE, Blackburn J, Marshall Graves JA, Mattick JS, Waters PD, et al. Differential intron retention in Jumonji chromatin modifier genes is implicated in reptile temperature-dependent sex determination. Sci Adv. 2017;3(6):e1700731.

Düsing C. Die Regulierung des Geschlechtsverhältnisses. Jena: Fischer; 1884.

Edwards A. Natural Selection and the Sex Ratio: Fisher's Sources. Am Nat. 1998;151(6):564-9.

Elf PK. Yolk steroid hormones and sex determination in reptiles with TSD. Gen Comp Endocrinol. 2003;132(3):349-55.

Escobedo-Galvan AH, Gonzalez-Salazar C, Lopez-Alcaide S, Arroyo-Pena VB, MartinezMeyer E. Will all species with temperaturedependent sex determination respond the same way to climate change? A reply to Kallimanis (2010). Oikos. 2011;120:795-9.

Ewert MA, Nelson CE. Sex determination in turtles: diverse patterns and some possible adaptive values. Copeia. 1991;1991(1):50-69.

Fisher RA. The genetical theory of natural selection. Oxford: Clarendon; 1930.

Frank SA, Swingland IR. Sex-ratio under conditional sex expression. J Theor Biol. 1988;135: 415-8.

Freedberg S, Debenport SJ. Weakened purifying selection leads to elevated mutation load under environmental sex determination. J Evol Biol. 2014;27(3):643-52.

Freedberg S, Taylor DR. Sex ratio variance and the maintenance of environmental sex determination. J Evol Biol. 2007;20(1):213-20.

Freedberg S, Wade MJ. Cultural inheritance as a mechanism for population sex-ratio bias in reptiles. Evolution. 2001;55(5):1049-55. 
Ge C, Ye J, Zhang H, Zhang Y, Sun W, Sang Y, et al. Dmrtl induces the male pathway in a turtle species with temperature-dependent sex determination. Development. 2017; 144(12): 2222-33.

Ge C, Ye J, Weber C, Sun W, Zhang H, Zhou Y, et al. The histone demethylase KDM6B regulates temperature-dependent sex determination in a turtle species. Science. 2018; 360(6389):645-8.

Georges A. Female turtles from hot nests: is it duration of incubation or proportion of development at high temperatures that matters? Oecologia. 1989;81(3):323-8.

Georges A, Limpus C, Stoutjesdijk R. Hatchling sex in the marine turtle Caretta caretta is determined by proportion of development at a temperature, not daily duration of exposure. J Exp Zool. 1994;270(5):432-44.

Georges A, Doody JS, Beggs K, Young JE. Thermal models of TSD under laboratory and field conditions. In: Valenzuela $\mathrm{N}$, Lance VA editors.Temperature-dependent sex determination in reptiles. Washington: Smithsonian Institute; 2004. p. 79-89.

Georges A, Beggs K, Young JE, Doody JS. Modelling development of reptile embryos under fluctuating temperature regimes. Physiol Biochem Zool. 2005;78(1):18-30.

Georges A, Ezaz T, Quinn AE, Sarre SD. Are Reptiles Predisposed to Temperature-Dependent Sex Determination?. Sex Dev. 2010;4(1-2):715.

Girondot M, Pieau C. Effects of sexual differences of age at maturity and survival on population sex ratio. Evol Ecol. 1993;7(6):645-50.

Girondot M, Pieau C. On the limits of age-structured models for the maintenance of environmental sex determination in crocodilians. Ann Sci Nat Zool. 1996;17:85-97.

Girondot M, Fouillet H, Pieau C. Feminizing turtle embryos as a conservation tool. Conserv Biol. 1998;12(2):353-62.

Girondot M, Delmas V, Rivalan P, Courchamp F, Prévot-Julliard A-C, Godfrey MH: Implication of temperature-dependent sex determination for population dynamics. In: Valenzuela N, Lance VA, editors. Temperature-dependent Sex Determination in Vertebrates. Washington: Smithsonian Books, 2004.

Grossen C, Neuenschwander S, Perrin N. Temperature-dependent turnovers in sex-determination mechanisms: a quantitative model. Evolution. 2011;65(1):64-78.

Haltenhof T, Kotte A, De Bortoli F, Schiefer S, Meinke S, Emmerichs AK, et al. A Conserved Kinase-Based Body-Temperature Sensor Globally Controls Alternative Splicing and Gene Expression. Mol Cell. 2020;78(1):57-69. e4.

Harts AM, Schwanz LE, Kokko H. Demography can favour female-advantageous alleles. Proc Biol Sci. 2014;281(1790):20140005.

Hawkes LA, Broderick AC, Godfrey MH, Godley $B J$. Investigating the potential impacts of climate change on a marine turtle population. Glob Change Biol. 2007;13(5):923-32.
Hays GC, Broderick AC, Glen F, Godley BJ. Climate change and sea turtles: a 150-year reconstruction of incubation temperatures at a major marine turtle rookery. Glob Change Biol. 2003;9(4):642-6.

Hays GC, Mazaris AD, Schofield G, Laloë JO Population viability at extreme sex-ratio skews produced by temperature-dependent sex determination. Proc Biol Sci. 2017; 284(1848):20162576

Holleley CE, O'Meally D, Sarre SD, Marshall Graves JA, Ezaz T, Matsubara K, et al. Sex reversal triggers the rapid transition from genetic to temperature-dependent sex. Nature. 2015;523(7558):79-82.

Holleley CE, Sarre SD, O'Meally D, Georges A. Sex reversal in reptiles: reproductive oddity or powerful driver of evolutionary change?. Sex Dev. 2016;10(5-6):279-87.

Hulin V, Guillon JM. Female philopatry in a heterogeneous environment: ordinary conditions leading to extraordinary ESS sex ratios. BMC Evol Biol. 2007;7:13.

Hulin V, Delmas V, Girondot M, Godfrey MH, Guillon JM. Temperature-dependent sex determination and global change: are some species at greater risk?. Oecologia. 2009;160(3): 493-506.

Hurley MA, Matthiessen P, Pickering AD. A model for environmental sex reversal in fish. J Theor Biol. 2004;227(2):159-65.

Janzen FJ. Heritable variation for sex ratio under environmental sex determination in the common snapping turtle (Chelydra serpentina). Genetics. 1992;131(1):155-61.

Janzen FJ. Climate change and temperature-dependent sex determination in reptiles. Proc Natl Acad Sci USA. 1994;91(16):7487-90.

Janzen FJ, Paukstis GL. Environmental sex determination in reptiles: ecology, evolution, and experimental design. Q Rev Biol. 1991;66(2): $149-79$.

Janzen FJ, Phillips PC. Exploring the evolution of environmental sex determination, especially in reptiles. J Evol Biol. 2006;19(6):1775-84.

Julliard R. Sex-specific dispersal in spatially varying environments leads to habitat-dependent evolutionary stable offspring sex ratios. Behav Ecol. 2000;11(4):421-8.

Kallimanis AS. Temperature dependent sex determination and climate change. Oikos. 2010; 119(1):197-200.

Korpelainen H. Sex ratios and conditions required for environmental sex determination in animals. Biol Rev Camb Philos Soc. 1990; 65(2): 147-84

Kuijper B, Pen I. Conflict over condition-dependent sex allocation can lead to mixed sex-determination systems. Evolution. 2014;68(11): 3229-47.

Leigh EGJr, Charnov EL, Warner RR. Sex ratio, sex change, and natural selection. Proc Natl Acad Sci USA. 1976;73:3656-60.

Leimar O, Van Dooren TJ, Hammerstein P. Adaptation and constraint in the evolution of environmental sex determination. J Theor Biol. 2004;227(4):561-70.
McGaugh SE, Janzen FJ. Effective heritability of targets of sex-ratio selection under environmental sex determination. J Evol Biol. 2011; 24(4):784-94.

Mitchell NJ, Kearney MR, Nelson NJ, Porter WP. Predicting the fate of a living fossil: how will global warming affect sex determination and hatching phenology in tuatara?. Proc Biol Sci. 2008;275(1648):2185-93.

Mitchell NJ, Allendorf FW, Keall SN, Daugherty $\mathrm{CH}$, Nelson NJ. Demographic effects of temperature-dependent sex determination: will tuatara survive global warming?. Glob Change Biol. 2010;16(1):60-72.

Morjan CL. How rapidly can maternal behavior affecting primary sex ratio evolve in a reptile with environmental sex determination?. Am Nat. 2003;162(2):205-19.

Patino-Martinez J, Marco A, Quiñones L, Hawkes L. A potential tool to mitigate the impacts of climate change to the caribbean leatherback sea turtle. Glob Change Biol. 2012;18(2):40111.

Pen I, Uller T, Feldmeyer B, Harts A, While GM, Wapstra E. Climate-driven population divergence in sex-determining systems. Nature. 2010;468(7322):436-8.

Pezaro N, Doody JS, Thompson MB. The ecology and evolution of temperature-dependent reaction norms for sex determination in reptiles: a mechanistic conceptual model. Biol Rev Camb Philos Soc. 2016;92(3):1348-64.

Pieau C. Temperature variation and sex determination in reptiles. Bioessays. 1996;18(1):1926.

Pieau C, Dorizzi M, Richard-Mercier N. Temperature-dependent sex determination and gonadal differentiation in reptiles. Cell Mol Life Sci. 1999;55(6-7):887-900.

Quinn AE, Sarre SD, Ezaz T, Marshall Graves JA, Georges A. Evolutionary transitions between mechanisms of sex determination in vertebrates. Biol Lett. 2011;7(3):443-8.

Radder RS, Pike DA, Quinn AE, Shine R. Offspring sex in a lizard depends on egg size. Curr Biol. 2009;19(13):1102-5.

Reinhold K. Sex-ratio selection with asymmetrical migration of the sexes can lead to an uneven sex ratio. Oikos. 1996;75(1):15-9.

Reinhold K. Nest-site philopatry and selection for environmental sex determination. Evol Ecol. 1998;12(2):245-50.

Rice WR. The accumulation of sexually antagonistic genes as a selective agent promoting the evolution of reduced recombination between primitive sex chromosomes. Evolution. 1987; 41(4):911-4.

Robert KA, Thompson MB, Seebacher F. Facultative sex allocation in the viviparous lizard Eulamprus tympanum, a species with temperature-dependent sex determination. Aust J Zool. 2003;51(4):367-70.

Saba VS, Stock CA, Spotila JR, Paladino FV, Tomillo PS. Projected response of an endangered marine turtle population to climate change. Nature Clim Change. 2012;2(11): 814-20.
Theoretical Conclusions on Sexual

Development and the Environment
Sex Dev 2021;15:7-22 
Sabath N, Itescu Y, Feldman A, Meiri S, Mayrose I, Valenzuela N. Sex determination, longevity, and the birth and death of reptilian species. Ecol Evol. 2016;6(15):5207-20.

Sánchez L, Chaouiya C. Primary sex determination of placental mammals: a modelling study uncovers dynamical developmental constraints in the formation of Sertoli and granulosa cells. BMC Syst Biol. 2016;10(1):37.

Sánchez L, Chaouiya C. Logical modelling uncovers developmental constraints for primary sex determination of chicken gonads. J R Soc Interface. 2018;15(142):20180165.

Sarre SD, Ezaz T, Georges A. Transitions between sex-determining systems in reptiles and amphibians. Annu Rev Genomics Hum Genet. 2011;12:391-406

Schwanz LE, Proulx SR. Mutual information reveals variation in temperature-dependent sex determination in response to environmental fluctuation, lifespan and selection. Proc Biol Sci. 2008;275(1650):2441-8.

Schwanz LE, Bragg JG, Charnov EL. Maternal condition and facultative sex ratios in populations with overlapping generations. Am Nat. 2006;168(4):521-30.

Schwanz LE, Janzen FJ, Proulx SR. Sex allocation based on relative and absolute condition. Evolution. 2010a;64(5):1331-45.

Schwanz LE, Spencer R-J, Bowden RM, Janzen FJ. Climate and predation dominate juvenile and adult recruitment in a turtle with temperature-dependent sex determination. Ecology. 2010b;91:3016-26.

Schwanz LE, Ezaz T, Gruber B, Georges A. Novel evolutionary pathways of sex-determining mechanisms. J Evol Biol. 2013;26(12):254457.
Schwanz LE, Cordero GA, Charnov EL, Janzen FJ. Sex-specific survival to maturity and the evolution of environmental sex determination. Evolution. 2016;70(2):329-41.

Schwanz LE, Georges A, Holleley CE, Sarre SD. Climate change, sex reversal and lability of sex-determining systems. J Evol Biol. 2020; 33(3):270-81

Shine R. Why is sex determined by nest temperature in many reptiles?. Trends Ecol Evol (Amst). 1999;14(5):186-9.

Trivers RL, Willard DE. Natural Selection of Parental Ability to Vary the Sex Ratio of Offspring. Science. 1973;179(4068):90-2.

Uller T, Helanterä H. From the origin of sex-determining factors to the evolution of sex-determining systems. Q Rev Biol. 2011;86(3): $163-80$.

Uller T, Pen I, Wapstra E, Beukeboom LW, Komdeur J. The evolution of sex ratios and sexdetermining systems. Trends Ecol Evol (Amst). 2007;22(6):292-7.

Valenzuela N. Evolution and maintenance of temperature-dependent sex determination. In: Valenzuela N, Lance VA, editors. Temperature Dependent Sex Determination in Vertebrates. Washington: Smithsonian Books; 2004. p. 131-147.

Valenzuela N, Literman R, Neuwald JL, Mizoguchi B, Iverson JB, Riley JL, et al. Extreme thermal fluctuations from climate change unexpectedly accelerate demographic collapse of vertebrates with temperature-dependent sex determination. Sci Rep. 2019;9(1):4254.

Van Dooren TJ, Leimar O. The evolution of environmental and genetic sex determination in fluctuating environments. Evolution. 2003; 57(12):2667-77.
Verma N, Verma BK, Pushpavanam S. Modeling temperature-dependent sex determination in oviparous species using a dynamical systems approach. Bull Math Biol. 2020;82(7):89.

Warner DA, Shine R. Reproducing lizards modify sex allocation in response to operational sex ratios. Biol Lett. 2007;3(1):47-50.

Warner DA, Shine R. The adaptive significance of temperature-dependent sex determination in a reptile. Nature. 2008;451(7178):566-8.

Warner DA, Lovern MB, Shine R. Maternal nutrition affects reproductive output and sex allocation in a lizard with environmental sex determination. Proc Biol Sci. 2007;274(1611): 883-90.

Warner DA, Uller T, Shine R. Fitness effects of the timing of hatching may drive the evolution of temperature-dependent sex determination in short-lived lizards. Evol Ecol. 2009;23(2): 281-94.

Weber C, Zhou Y, Lee JG, Looger LL, Qian G, Ge $\mathrm{C}$, et al. Temperature-dependent sex determination is mediated by pSTAT3 repression of Kdm6b. Science. 2020;368(6488):303-6.

West S. Sex Allocation. Princeton: Princeton University Press; 2009.

Witt MJ, Hawkes LA, Godfrey MH, Godley BJ, Broderick AC. Predicting the impacts of climate change on a globally distributed species: the case of the loggerhead turtle. J Exp Biol. 2010;213(6):901-11.

Woodward DE, Murray JD. On the effect of temperature-dependent sex determination on sex ratio and survivorship in crocodilians. Proc $\mathrm{R}$ Soc Lond B. 1993;252:149-55.

Yamaguchi S, Iwasa Y. Temperature-dependent sex determination, realized by hormonal dynamics with enzymatic reactions sensitive to ambient temperature. J Theor Biol. 2018;453: $146-55$. 